Adaptive Selling: Conceptualization, Measurement, and Nomological Validity

Author(s): Rosann L. Spiro and Barton A. Weitz

Source: Journal of Marketing Research, Vol. 27, No. 1 (Feb., 1990), pp. 61-69

Published by: American Marketing Association

Stable URL: http://www.jstor.org/stable/3172551

Accessed: 03/03/2010 15:13

Your use of the JSTOR archive indicates your acceptance of JSTOR's Terms and Conditions of Use, available at http://www.jstor.org/page/info/about/policies/terms.jsp. JSTOR's Terms and Conditions of Use provides, in part, that unless you have obtained prior permission, you may not download an entire issue of a journal or multiple copies of articles, and you may use content in the JSTOR archive only for your personal, non-commercial use.

Please contact the publisher regarding any further use of this work. Publisher contact information may be obtained at http://www.jstor.org/action/showPublisher?publisherCode=ama.

Each copy of any part of a JSTOR transmission must contain the same copyright notice that appears on the screen or printed page of such transmission.

JSTOR is a not-for-profit service that helps scholars, researchers, and students discover, use, and build upon a wide range of content in a trusted digital archive. We use information technology and tools to increase productivity and facilitate new forms of scholarship. For more information about JSTOR, please contact support@jstor.org. 
A 16-item scale is developed to measure the degree to which salespeople practice adaptive selling-the degree to which they alter their sales presentation across and during customer interactions in response to the perceived nature of the sales situation. This paper-and-pencil scale assesses self-reports of five facets of adaptive selling: (1) recognition that different sales approaches are needed for different customers, (2) confidence in ability to use a variety of approaches, (3) confidence in ability to alter approach during an interaction, (4) collection of information to facilitate adaptation, and (5) actual use of different approaches. The reliability of the scale is $\mathbf{8 5}$. Support for the nomological validity of the scale is found by failure to disconfirm relationships with an antecedent (intrinsic motivation), several general personality measures of interpersonal flexibility (self-monitoring, empathy, locus of control, and androgyny), and a consequence (self-reported performance).

\section{Adaptive Selling: Conceptualization, Measurement, and Nomological Validity}

Personal selling is the only communication vehicle that allows a marketing message to be adapted to the specific needs and beliefs of each customer. The ISTEA model (Weitz 1978) emphasizes this adaptive nature by suggesting that the selling process consists of collecting information about a prospective customer, developing a sales strategy based on this information, transmitting messages to implement the strategy, evaluating the impact of these messages, and making adjustments based on this evaluation. Thus, salespeople have an opportunity to develop and implement a sales presentation tailored to each customer. In addition, salespeople can make rapid adjustments in the message in response to their customers' reactions.

Other marketing communication vehicles (mass media, sales promotions, point-of-purchase displays, packaging) are restricted to delivery of messages targeted toward a "typical" customer in a market segment. The opportunity to make adjustments in messages delivered

* Rosann L. Spiro is Associate Professor of Marketing, Indiana University. Barton A. Weitz is Professor of Marketing and J. C. Penny Eminent Scholar Chair, University of Florida.

The authors acknowledge Scott MacKenzie (Indiana University) for his valuable inputs to this project. through these vehicles is limited by the substantial delays in monitoring customer reactions and developing new communication programs. Because of its adaptive capability, personal selling is the most effective communication vehicle; however, this effectiveness is achieved at significant costs. The cost of delivering a message per person contacted through personal selling far surpasses the cost of delivering messages through mass media (Stanton 1984).

Most empirical research on personal selling has ignored the unique adaptive capability of personal selling. Rather than focusing on the antecedents and consequences of adaptation, empirical research has been directed toward uncovering universally effective sales behaviors and behavioral predispositions. As one might expect, this research direction has been largely unsuccessful in uncovering sales behaviors that are effective over a wide range of selling situations (Weitz 1979). In fact, had this research identified a set of universally effective selling behaviors, it would have resulted in the adoption of standardized communication approaches ("canned" presentations) that could be delivered more cost effectively than personal selling.

The object of our research is to develop and validate a measure of the degree to which salespeople practice adaptive selling-the degree to which they attempt to 
exploit the unique properties of personal selling. After defining the construct of adaptive selling, we discuss some antecedents and consequences of this construct. Then a paper-and-pencil, self-report measure of adaptive selling is developed on the basis of a survey of 250 salespeople. The nomological validity of these measures is assessed by examining relationships of the adaptive selling measure to antecedents, consequences, and general personality measures of interpersonal flexibility. We conclude with managerial implications and directions for future research.

\section{CONCEPTUALIZATION OF ADAPTIVE SELLING}

\section{Definition}

"The practice of adaptive selling is defined as the altering of sales behaviors during a customer interaction or across customer interactions based on perceived information about the nature of the selling situation" (Weitz, Sujan, and Sujan 1986). Salespeople exhibit a high level of adaptive selling when they use different sales presentations across sales encounters and when they make adjustments during the encounters. In contrast, a low level of adaptive selling is indicated by the use of the same sales presentation in and during all sales encounters.

By this definition, adaptive selling can be undertaken in an effective and an ineffective way; hence effectiveness is not part of the definition. Adaptive selling results in long-term effectiveness when the benefits of the approach outweigh the costs-when the sales generated through the practice of adaptive selling outweigh the cost of selecting and training salespeople to collect relevant information from their customers and utilize this information appropriately. Four conditions under which the benefits are likely to outweigh the costs are when (1) salespeople encounter a wide variety of customers with different needs, (2) the typical sales situation involves large orders, (3) the company provides resources to facilitate adaptation, and (4) the salespeople have the capability to adapt effectively (Weitz, Sujan, and Sujan 1986).

We hypothesize that:

$\mathrm{H}_{1}$ : The practice of adaptive selling results in better sales performance.

Empirical support for this hypothesis is provided by Sujan and Weitz (1986), who found a significant relationship between "working smarter" and performance. "Working smarter" was operationalized as the practice of adaptive selling.

\section{Aspects of Adaptive Selling}

To develop a measure of the degree to which salespeople are predisposed to practice adaptive selling, we propose that this predisposition consists of the following six facets.

1. A recognition that different selling approaches are needed in different sales situations.
2. Confidence in the ability to use a variety of different sales approaches.

3. Confidence in the ability to alter the sales approach during a customer interaction.

4. A knowledge structure that facilitates the recognition of different sales situations and access to sales strategies appropriate for each situation.

5. The collection of information about the sales situation to facilitate adaptation.

6. The actual use of different approaches in different situations.

The first three facets pertain to the motivation of salespeople to practice adaptive selling. Salespeople first must believe that customers have different beliefs and needs and that these customer differences result in a need to alter sales presentations accordingly. The degree to which salespeople are motivated to alter their sales approaches across selling situations will be based, to a large extent, on their expectation that doing so will lead to greater sales. Therefore, they must have confidence in their ability to utilize a wide variety of sales approaches, confidence in their ability to recognize when a particular approach is needed and when a particular approach is not working, and confidence in their ability to alter a sales approach when it is perceived to be ineffective.

The fourth and fifth facets are related to the capabilities needed to practice adaptive selling effectively. These capabilities consist of (1) an elaborate knowledge structure of sales situations that enables salespeople to recognize different types of categories of situations and to retrieve, from memory, an appropriate sales approach associated with the category and (2) an ability to collect information to facilitate the process of matching sales situations to categories in memory (Weitz, Sujan, and Sujan 1986). Salespeople having these capabilities will be effective in practicing adaptive selling and their positive experiences will reinforce the continued practice of adaptive selling.

Finally, the sixth facet pertains to the actual behavior of salespeople. Salespeople who have practiced adaptive selling in the past will be predisposed to continue to practice adaptive selling.

\section{Adaptation and Sales Process Models}

Most conceptual models of the sales process explicitly incorporate the notion of adaptive selling in the form of feedback loops and interactions between sales behaviors and characteristics of the sales encounter. For example, the Spiro, Perreault, and Reynolds (1976) model of a dyadic sales interaction includes a decision node at which the compatibility of the needs and expectations of the buyer and seller is tested. An exchange occurs when compatibility is present. However, when the needs and expectations are incompatible, either negotiations can be terminated or the parties in the negotiation must adapt by altering either their negotiation strategies or their needs and expectations.

The ISTEA model (Weitz 1978) focuses on the sales- 
person's behavior rather than the dyadic interaction. This model also includes an adjustment stage that follows the evaluation stage and may result in changing the salesperson's impression of the customer, the strategy used to sell the customer, or the specific message delivered. In this model, a sales encounter is conceptualized as cycling through the adjustment stage multiple times during an interaction.

In addition, adaptation has a central role in a widely used sales training program (Ingrasci 1981) based on the communication style matrix (Merrill and Reid 1981). In this program, salespeople are classified and are trained to classify customers on three dimensions: (1) responsiveness, (2) assertiveness, and (3) flexibility. On the basis of these dimensions, the salespeople are instructed to use cues to categorize customers and to adjust their communication style to match the customer's communication style.

\section{Empirical Research}

Though empirical research has not investigated adaptive selling directly, some research indicates that salespeople practice adaptive selling. For example, Spiro and Perreault (1979) found that a variety of sales approaches are used by salespeople and that the different approaches are related to the nature of the sales encounter.

\section{FACTORS RELATED TO THE PRACTICE OF ADAPTIVE SELLING}

In this section, we discuss some personality traits and managerial activities that are related conceptually to the practice of adaptive selling. The hypotheses developed in this section form a basis for examining the nomological validity of the measure we develop.

\section{Personality Traits and Adaptive Selling}

The following general personality traits reflect aspects of interpersonal flexibility and hence are proposed to be related to the degree to which a salesperson practices adaptive selling: (1) self-monitoring, (2) empathy, (3) androgyny, (4) being an opener, and (5) locus of control. Though the usefulness of personality trait measures for predicting sales performance has been questioned (Weitz 1979), the specific traits we examine differ from the traits considered in previous sales research. Rather than examining traits related conceptually to a specific behavior such as aggressiveness or sociability, we are considering only traits related conceptually to flexibility in behaviors.

Self-monitoring. The theory of self-monitoring (Snyder 1979) suggests that individuals have a consistent pattern in terms of the degree to which they alter their selfpresentation in response to situational cues. Hence, people who are high in self-monitoring should demonstrate more cross-situational variability in behavior than people who are low in self-monitoring. Lennox and Wolfe (1984) developed a revised self-monitoring scale consisting of four subscales assessing (1) ability to modify self-presentation, (2) sensitivity to expressive behavior by oth- ers, (3) cross-situational variability, and (4) attention to social comparison information.

Three of these aspects of self-monitoring are related directly to some of the elements describing adaptive selling discussed previously, such as the use of different sales strategies across situations, sensitivity to customer reactions, and adaptation during interactions. Therefore,

$\mathrm{H}_{2}$ : The degree to which salespeople are self-monitors is related positively to their practice of adaptive selling. The aspects of self-monitoring related to adaptive selling behavior are (a) ability to modify self-presentation, (b) sensitivity to expressive behavior in others, and (c) cross-situational variability.

The fourth aspect of self-monitoring, attention to social comparison information, is not considered because of the conceptual difference between attempts to emulate the behavior and dress of other individuals in a social setting and the analogous concept of attempting to uncover and satisfy customer needs in an industrial sales setting.

Androgyny. Androgyny has been defined as the degree to which individuals feel that they are characterized by traits culturally associated with both men and women. Androgynous people perceive themselves as being both assertive and yielding and both instrumental and expressive. For the androgynous person, the specific interaction pattern adopted depends on the situational appropriateness of the behavior. In contrast, the interaction pattern of strongly sex-typed individuals is limited because of their desire to engage only in behaviors associated with their perceived sex role (Bem 1974). Hence, androgyny is related to flexibility in interpersonal interactions - an aspect of adaptive selling. Empirical support for the relationship between androgyny and interpersonal flexibility is provided by Wiggins and Holzmuller (1981).

$\mathrm{H}_{3}$ : The degree to which salespeople are androgynous is related positively to their practice of adaptive selling.

Empathy. Empathy, at the most general level, is the reaction of individuals to the observed experiences of other individuals. Observers can have a variety of potential reactions. Davis (1983) has distinguished between four types of reactions: (1) perspective taking, (2) fantasy, (3) empathetic concern, and (4) personal distress.

The fantasy and personal distress aspects of empathy appear to be unrelated to the practice of adaptive selling; however, perspective taking and empathetic concern are associated with aspects of adaptive selling such as the perception that customers differ in terms of needs (first facet) and the collection of information to facilitate adaptation (fifth facet).

Additionally, Johnson, Cheek, and Smither (1983) reanalyzed Hogan's (1969) original empathy scale and found four distinct factors: sensitivity, even temperedness, nonconformity, and social self-confidence. The sensitivity items on the first subscale are conceptually the same as the empathetic concern dimension discussed 
before. The items on the second and third subscales do not seem appropriate in a business context or to be related to the practice of adaptive selling.

The items on the fourth dimension, social self-confidence, seemingly are related to the practice of adaptive selling. Social self-confidence indicates the degree to which an individual is confident in social situations. In general, people who are socially self-confident also perceive themselves as being socially adept, assertive, and perhaps slightly overbearing and impulsive. Consequently, one would expect socially self-confident salespeople to be more confident in their ability to use different sales approaches and to alter sales approaches (second and third facets).

$\mathrm{H}_{4}$ : The degree to which salespeople are empathetic in terms of (a) perspective taking, (b) empathetic concern, and (c) social self-confidence is related positively to their practice of adaptive selling.

Openers. Miller, Berg, and Archer (1983) suggest that individuals differ in the degree to which they are predisposed to "open up" or elicit intimate information from other people. That is, some people seem to be more able to get others to talk about themselves. This "openers" personality trait is related conceptually to the active collection of information about customer needs in adaptive selling (fifth facet).

$\mathrm{H}_{5}$ : The degree to which salespeople are openers is related positively to their practice of adaptive selling.

Locus of control. Rotter (1966) conceptualized locus of control as a predisposition in the perception of what caused a reward (or favorable outcome) and how individuals react to the reward on the basis of this perception. Beliefs that rewards are typically due to luck, chance, or fate or are simply unpredictable indicate an external locus of control. An internal locus of control is associated with a tendency to perceive that rewards are typically the results of one's own behavior.

Paulhas (1983) has proposed that locus of control can be partitioned into three aspects: (1) personal efficacy, (2) interpersonal control, and (3) sociopolitical control. Conceptually, personal efficacy and interpersonal locus of control are related to the confidence salespeople have in using different approaches and adapting during interactions (fourth facet).

$\mathrm{H}_{6}$ : The degree to which salespeople have an internal locus of control over personal efficacy and interpersonal situations is related positively to their practice of adaptive selling.

\section{Antecedents of Adaptive Selling}

Three proposed antecedents of adaptive selling are knowledge gained through experience, a motivation to acquire knowledge and develop skills based on an intrinsic interest in the job, and management style of the immediate supervisor.

Intrinsic motivation. Intrinsic motivation is defined as the motivation to seek "rewards derived directly from or inherent in the task or job itself-associated with the content of the task or job," whereas extrinsic motivation is the motivation to seek "rewards derived from the environment surrounding the task or work-associated with the context of the task or job" (Dyer and Parker 1975). Hence salespeople who are intrinsically motivated find selling inherently rewarding. Because of this inherent interest in selling, Weitz, Sujan, and Sujan (1986) propose that intrinsically motivated salespeople will be motivated to practice adaptive selling by their drive to be creative and to gain mastery over their job. Sujan and Weitz (1986) provide empirical support for this hypothesis.

$\mathrm{H}_{7}$ : The degree to which salespeople are intrinsically motivated positively affects their practice of adaptive selling.

Experience. Through experience, salespeople improve their skills and develop a more elaborate knowledge of selling situations, customer types, and potential selling strategies (Weitz, Sujan, and Sujan 1986). This extensive knowledge base enables salespeople to recognize a wider variety of selling situations and thus facilitates the practice of adaptive selling.

$\mathrm{H}_{8}$ : The experience of salespeople positively affects their practice of adaptive selling.

Management styles. In the preceding sections, we develop hypotheses about the relationship of salesperson characteristics to the practice of adaptive selling and sales performance. In this section, we suggest how management styles affect the practice of adaptive selling.

On the basis of a theory of role differentiation and group achievement (Stogdill 1959), 12 dimensions of supervisory (leader) behavior have been identified. We hypothesize that three of these dimensions are relevant to our study. The "initiation of structure" and "production emphasis" can inhibit the practice of adaptive selling. Managers employing these supervisory styles may constrain the behavior of salespeople, encouraging them to use a well-defined set of sales approaches and discouraging experimentation with new approaches. In contrast, "tolerance of freedom" might encourage the practice of adaptive selling.

$\mathrm{H}_{9}$ : The practice of adaptive selling by salespeople is affected positively by the degree to which sales managers tolerate freedom of action.

$\mathrm{H}_{10}$ : The practice of adaptive selling is affected negatively by the degree to which sales managers initiate structure.

$\mathrm{H}_{11}$ : The practice of adaptive selling is affected negatively by the degree to which sales managers emphasize production.

\section{SCALE DEVELOPMENT}

In this section, we describe the development and properties of the scale measuring the degree to which salespeople practice adaptive selling. The nomological validity of the scale is examined in the next section. 


\section{Procedure}

The adaptive selling scale (ADAPTS) was developed by a procedure similar to the one suggested by Nunnally (1978). A pool of 42 items were generated to assess the six aspects of adaptive selling discussed before. Developing self-report scale items to assess the knowledge structure of salespeople (facet 5) was difficult. Measures of knowledge structure typically involve card-sorting tasks or active elicitation of information in memory (Weitz, Sujan, and Sujan 1986). As our objective was to develop a paper-and-pencil assessment that could be measured easily and uniformly, items to assess facet 5 were restricted to measures of the degree to which salespeople categorize sales situations. We measured categorization because it is related intimately to knowledge development (Weitz, Sujan, and Sujan 1986) and can be assessed by a paper-and-pencil method.

A questionnaire containing these items and scales measuring constructs for assessing nomological validity were distributed to salespeople in 10 divisions of a major national manufacturer of diagnostic equipment and supplies. As confirmed by pretest interviews, these salespeople continually encounter a wide variety of selling situations in which the practice of adaptive selling should be beneficial. The questionnaires were distributed by the firm but returned, anonymously, directly to the researchers. Of the 500 questionnaires distributed, 268 were returned in a usable form for a $54 \%$ response rate.

The 42 items were subjected to a principal component analysis and a factor analysis for which the communalities were estimated. The eigenvalues of the first five components were $7.24,2.36,1.91,1.27$, and 1.07. The pattern of loadings for the principal component analysis and the factor analysis did not correspond to the conceptualized facets of adaptive selling discussed before. However, items representing five of the six facets did load highly on the first component. Therefore, on the basis of these results and given the break in eigenvalues between the first and second components, we decided to develop one scale encorporating all of the facets rather than separate scales for each facet. We followed an itemreduction procedure to construct this scale. The objectives of the item-reduction procedure were to produce a scale with (1) highly intercorrelated items, (2) items representing all conceptualized facets of adaptive selling, (3) items loading highly on the first principal component, (4) a scale mean as close as possible to the scale midpoint (4.0), (5) a high standard deviation, (6) a minimum number of items, and (7) a high reliability. One limitation of this procedure is that the items loading on the first principal component may reflect a degree of common method variance arising from a correlation between mean item response and item standard deviation. However, this potential source of common method variance is present in all scale development for which high reliability is an objective.

The final 16-item scale that best met the objectives is shown in Table 1. The mean response for the scale (sum divided by number of items) is 5.51 , the standard deviation is .66 , and the Cronbach alpha is .85 . Because the 16-item scale is not unidimensional on the basis of statistical tests using confirmatory factor analysis, caution is warranted when using Cronbach alpha as a measure of reliability. When these 16 items are subjected to a principal component analysis, the eigenvalues of the first two components are 4.59 and 1.12.

The final scale contains at least two items from five of the six facets described before. Items related to the fourth facet, knowledge structure, are not represented in the final scale because these items assessing categorizations are unrelated to the 16 items forming the final scale. Perhaps salespeople have difficulty responding to categorization items, as theory suggests that the categorization and retrieval processes are done unconsciously by experienced (expert) salespeople.

\section{NOMOLOGICAL VALIDITY}

To test the hypotheses and investigate the nomological validity of the scale, we examined the simple correlations between ADAPTS and the measures of personality, intrinsic motivation, experience, management style, and performance.

\section{Measures}

The 268 salespeople used to develop the adaptive selling scale also responded to questions used to validate the scales. Ideally, Nunnally (1978) recommends that a separate sample be used to validate the scale; however, resource and access limitations prohibited using separate samples. Multi-item scales were used to measure most of the constructs.

Personality. Most of the personality measures-selfmonitoring, androgyny, empathy, being an opener, and locus of control-were assessed by using well-established scales that have been validated in a wide variety of studies. The source, mean, standard deviation, and reliability of these measures are reported in Table 2.

Intrinsic motivation. A 7-item scale developed for the study was used to measure intrinsic motivation. The items were designed to indicate the degree to which the salesperson was motivated by rewards arising from the task itself. Examples of items in this scale are "selling is not fun" (reversed), "selling a customer is like playing a game," and "interacting with customers is exciting and challenging."

Experience. Experience was measured by a self-report of the number of months that a salesperson had worked for the firm in a sales capacity.

Managerial style. The three dimensions of managerial style were measured by using the LBDQXII scales (Stogdill 1963). These measures are based on the salesperson's perception of his or her sales manager's behavior. Though the psychometric properties of these scales have been questioned, they are the most widely used 
Table 1

ITEMS AND CHARACTERISTICS OF ADAPTS

\begin{tabular}{|c|c|c|c|c|c|}
\hline $\begin{array}{c}\text { Item } \\
\text { no. }\end{array}$ & Items & $\begin{array}{c}\text { Facet of } \\
\text { adaptive } \\
\text { selling }\end{array}$ & Mean & S.D. & $\begin{array}{c}\text { Item-to- } \\
\quad \text { total } \\
\text { correlation }\end{array}$ \\
\hline 5. & Each customer requires a unique approach & 1 & 5.73 & 1.25 & .39 \\
\hline 10. & When I feel that my sales approach is not working, I can easily & & & & \\
\hline & change to another approach & 3 & 5.27 & 1.19 & .43 \\
\hline 14. & I like to experiment with different sales approaches & 6 & 5.07 & 1.30 & .47 \\
\hline 16. & I am very flexible in the selling approach I use & 6 & 5.67 & 1.03 & .54 \\
\hline 17. & I feel that most buyers can be dealt with in pretty much the same & & & & \\
\hline & manner & $1^{\mathrm{a}}$ & 5.54 & 1.30 & .46 \\
\hline 25. & I don't change my approach from one customer to another & $6^{\mathrm{a}}$ & 5.90 & 1.23 & .44 \\
\hline 28. & I can easily use a wide variety of selling approaches & 2 & 5.25 & 1.22 & .59 \\
\hline 31. & I use a set sales approach & $6^{\mathrm{a}}$ & 5.40 & 1.28 & .38 \\
\hline 33. & It is easy for me to modify my sales presentation if the situation & & & & \\
\hline & calls for it & 3 & 5.53 & 1.07 & .57 \\
\hline 34. & Basically I use the same approach with most customers & $6^{\mathrm{a}}$ & 4.97 & 1.54 & .47 \\
\hline 35. & I am very sensitive to the needs of my customers & 5 & 6.07 & 1.06 & .41 \\
\hline 36. & I find it difficult to adapt my presentation style to certain buyers & $2^{\mathrm{a}}$ & 4.95 & 1.49 & .33 \\
\hline 37. & I vary my sales style from situation to situation & 6 & 5.63 & 1.10 & .61 \\
\hline 38. & I try to understand how one customer differs from another & 5 & 5.78 & 1.15 & .45 \\
\hline 39. & I feel confident that I can effectively change my planned presen- & & & & \\
\hline & tation when necessary & 3 & 5.83 & .91 & .50 \\
\hline 42. & I treat all of my buyers pretty much the same & $6^{\mathrm{a}}$ & 5.42 & 1.49 & .43 \\
\hline
\end{tabular}

${ }^{a}$ Reverse scored.

measures of supervisory behavior in sales and management research.

Performance. Two measures of performance, self-report and a manager-provided assessment, were examined. Each salesperson provided a self-report measure of performance by responding to a 5-point scale anchored by "near the bottom" and "near the top" with an "average" midpoint. In a separate questionnaire, the firstline sales managers evaluated each salesperson reporting to them on a 5-point scale anchored by "distinguished" and "marginal." These two performance measures are not necessarily assessing similar aspects of performance. Because the two global measures of performance are supplied by two different people who hold two different positions in the company, their perspectives on which aspects of the sales job are most important are likely to differ and hence their global ratings probably differ also (Landy and Farr 1980).

Churchill et al. (1985) state, as a result of their metaanalysis of sales performance determinants, that self-report measures of sales performance do not demonstrate any particular upward bias. In fact, they conclude that there is no evidence in favor of using any one particular measure instead of another. Other researchers (Behrman and Perreault 1982; Landy and Farr 1980) have noted the inadequacies of performance measures in general. Therefore, because two global measures, each of which may be emphasizing different aspects of performance and each of which has its own particular biases, are better than one, we examined these two measures separately.

\section{RESULTS}

Table 3 is the correlation matrix for ADAPTS and the general personality measures of interpersonal flexibility, experience, intrinsic motivation, and management supervisory style. The correlations between ADAPTS and these measures support the nomological validity of the ADAPTS scale. ADAPTS is correlated significantly ( $p$ $<.001$ ) with eight general measures of interpersonal flexibility. Only the cross-situational variability in behavior aspect of the self-monitoring construct is not related to ADAPTS. This lack of relationship may be due to differences in the concept of interpersonal flexibility in business (sales) situations and the social environment examined by items in the self-monitoring scales.

ADAPTS is related significantly $(p<.001)$ to one proposed antecedent, intrinsic motivation, but not to experience or managerial style. The lack of relationship with experience may be due to a ceiling effect. As the mean experience of respondents is only eight years, they may not be differentiated in terms of knowledge gained through experience. Managerial style, as measured in this study, does not seem to affect the degree to which salespeople practice adaptive selling.

Finally, the relationship between ADAPTS and performance is unconclusive. Though ADAPTS is related significantly $(p<.001)$ to a self-assessment of performance, it is unrelated to the management ratings of performance. The management ratings of performance are related to only two variables considered in our re- 
search-social self-confidence and the production orientation of the managers. The correlation between selfreport performance and the sales-specific measure of adaptability is greater in all cases than the correlation between general measures of interpersonal flexibility and self-reported performance. Hence, though general measures are related to ADAPTS, ADAPTS may be more useful in diagnosing performance in a sales environment.

\section{DISCUSSION}

The adaptive selling scale (ADAPTS) developed in our research assesses the degree to which salespeople adapt their sales presentation in response to characteristics of the sales situation. The psychometric properties indicate that the ADAPTS scale can be useful for managerial activities and academic research. However, additional research is needed to investigate further the validity of the scale. Weitz, Sujan, and Sujan (1986) developed several hypotheses about antecedents and consequences of adaptive selling that can be examined to substantiate nomological validity. Finally, norms for the scale should be established for salespeople involved in different sales environments and at different stages of their career life cycles.

Note that the mean rating for our sample of salespeople is very high, 5.51; however, there is sufficient variability to uncover significant relationships. We believe the high adaptability ratings reflect the professional ex- perience of the salesforce surveyed, but the high mean rating may be due to response bias.

The fourth facet of adaptive selling, knowledge structure, is not incorporated in the ADAPTS scale. Perhaps this facet is difficult to assess by paper-and-pencil, "agreedisagree" scales. Paulhas and Marlin (1988) have suggested a method of measuring functional flexibility that can be used in tapping this aspect of adaptive selling. Functional flexibility is a person's capability to adjust his or her behaviors to the demands of a broad range of situations. This concept is related closely to the function provided by an elaborate knowledge structure as outlined by Weitz, Sujan, and Sujan (1986).

The ADAPTS scale, with additional assessment of its predictive validity, could be a useful diagnostic tool for sales management. In sales environments benefiting from adaptive selling, the measures could be used to indicate whether poor sales performance is due to a lack of flexibility in sales approaches. In addition, the scales can serve as a method for evaluating sales management programs. For example, sales training programs can be evaluated by comparing adaptive selling scores obtained before and after the program.

Because the scale assesses the practice of salespeople, it is not useful in screening or selecting candidates for sales positions who do not have sales experience. However, our research indicates that some personality traitsandrogyny, locus of control, empathy, intrinsic motivation, and self-monitoring - are related significantly to

Table 2

SUMMARY OF MEASURES

\begin{tabular}{|c|c|c|c|c|}
\hline Measure (source) & $\begin{array}{c}\text { No. of } \\
\text { items }\end{array}$ & Mean & S.D. & $\begin{array}{c}\text { Reliability } \\
\text { (Cronbach's } \\
\text { alpha) }\end{array}$ \\
\hline $\begin{array}{l}\text { Adaptive selling } \\
\text { Performance }\end{array}$ & 16 & 5.51 & .66 & .85 \\
\hline Self-rating & 1 & 4.41 & .66 & - \\
\hline Manager rating & 1 & 3.49 & .67 & - \\
\hline \multicolumn{5}{|l|}{ Self-monitoring (Lennox and Wolfe 1984) } \\
\hline Ability to modify self-presentation & 7 & 5.25 & .72 & .77 \\
\hline Sensitivity to expressive behaviors in others & 6 & 5.32 & .76 & .81 \\
\hline Cross-situational variability & 3 & 4.21 & 1.22 & .87 \\
\hline Androgyny (Bem 1981) & 20 & 32.40 & 5.85 & - \\
\hline \multicolumn{5}{|l|}{ Empathy } \\
\hline Perspective taking (Davis 1980) & 7 & 5.19 & .76 & .77 \\
\hline Empathetic concern (Davis 1980) & 7 & 5.29 & .77 & .71 \\
\hline Social self-confidence (Johnson, Cheek, and Smither 1983) & 5 & 5.49 & .82 & .79 \\
\hline Openers (Miller, Berg, and Archer 1983) & 10 & 5.79 & .63 & .89 \\
\hline Intrinsic motivation & 7 & 6.08 & .70 & .79 \\
\hline \multicolumn{5}{|l|}{ Locus of control (Paulhaus 1983) } \\
\hline Personal efficacy & 10 & 5.64 & .60 & .68 \\
\hline Interpersonal control & 10 & 5.55 & .61 & .76 \\
\hline Experience & 1 & 101.57 & 80.34 & - \\
\hline \multicolumn{5}{|l|}{ Management style (Stogdill 1963) } \\
\hline Tolerance of freedom & 10 & 5.96 & .76 & .91 \\
\hline Initiation of structure & 10 & 4.40 & .68 & .70 \\
\hline Production emphasis & 10 & 4.46 & .76 & .75 \\
\hline
\end{tabular}




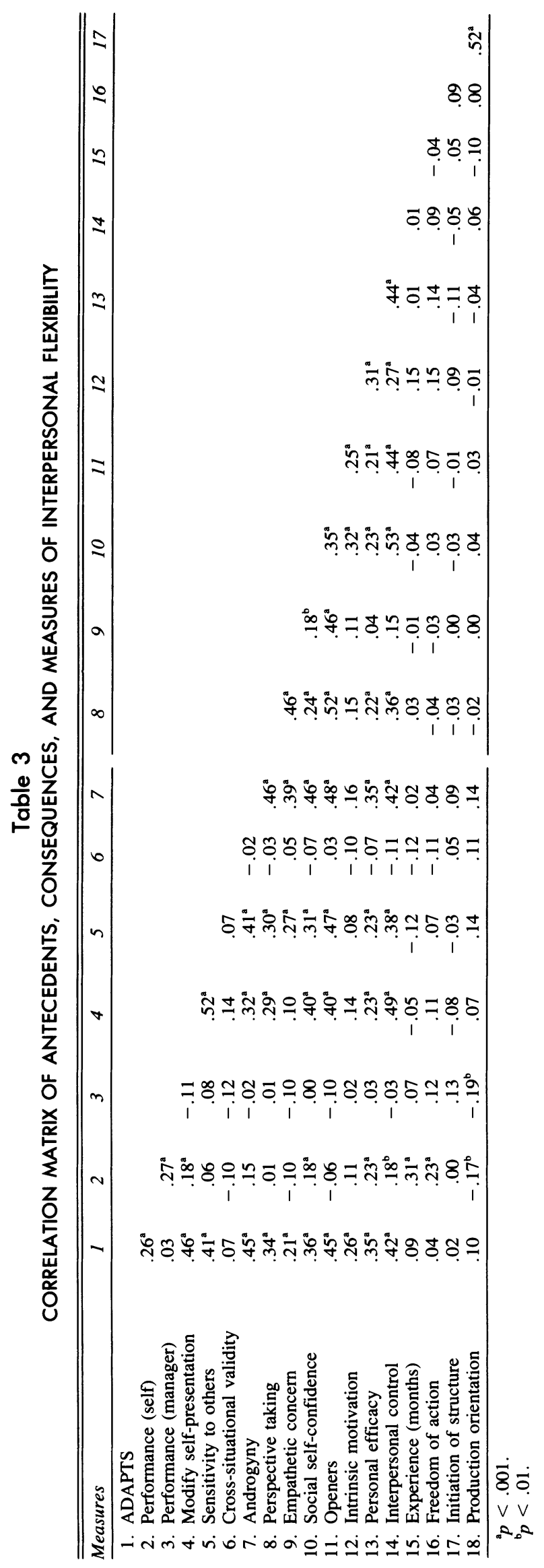


the practice of adaptive selling. With additional validation, these personality measures could be used as selection tests to determine the adaptive selling potential of inexperienced sales candidates.

The study of antecedents and consequences of adaptive selling is a promising direction for research on salesperson effectiveness. For example, Weitz, Sujan, and Sujan (1986) emphasize that the practice of adaptive selling is related intimately to the knowledge structure of salespeople. They suggest that (1) the mere practice of adaptive selling results in a more elaborate knowledge structure through a trial-and-error learning process and (2) knowledge structure moderates the relationship between adaptive selling and sales performance because knowledge is needed to make effective adaptations. With the ADAPTS scale to measure adaptive selling, these propositions can be explored empirically.

\section{REFERENCES}

Behrman, Douglas N. and William D. Perreault, Jr. (1982), "Measuring the Performance of Industrial Salespersons," Journal of Business Research, 10 (September), 355-69.

Bem, Sandra Lipsitz (1974), "The Measurement of Psychological Androgyny," Journal of Consulting and Clinical Psychology, 42 (April), 155-62.

(1981), Bem Sex-Role Inventory. Palo Alto, CA: Consulting Psychologists Press.

Churchill, Gilbert A., Jr., Neil M. Ford, Steven Hartley, and Orville C. Walker, Jr. (1985), "The Determinants of Salesperson Performance: A Meta-Analysis," Journal of Marketing Research, 22 (May), 103-18.

Davis, Mark H. (1980), "A Multidimensional Approach to Individual Differences in Empathy," JSAS Catalog of Selected Documents in Psychology, 10, 85.

(1983), "Measuring Individual Differences in Empathy: Evidence for a Multi-Dimensional Approach," Journal of Personality and Social Psychology, 44 (January), 11326.

Dyer, Lee and Donald F. Parker (1975), "Classifying Outcomes in Work Motivation Research: An Examination of the Intrinsic-Extrinsic Dichotomy," Journal of Applied Psychology, 60 (August), 455-8.

Hogan, R. (1969), "Development of an Empathy Scale," Journal of Consulting and Clincial Psychology, 33, 30716.

Ingrasci, Hugh J. (1981), "How to Reach Buyers in Their Psychological 'Comfort Zone'," Industrial Marketing, 66 (July), 60-4.

Johnson, John A., Jonathan M. Cheek, and Robert Smither (1983), "The Structure of Empathy," Journal of Personality and Social Psychology, 45 (December), 1299-1312.

Landy, Frank J. and James L. Farr (1980), "Performance Rating," Psychological Bulletin, 87, 72-107.

Lennox, Richard D. and Raymond N. Wolfe (1984), "Revision to the Self-Monitoring Scale," Journal of Personality and Social Psychology, 46 (June), 1349-69.

Merrill, David W. and Roger H. Reid (1981), Personal Styles and Effective Performance. Radnor, PA: Chilton Book Company.

Miller, Lynn Carol, John H. Berg, and Richard L. Archer (1983), "Openers: Individuals Who Elicit Intimate Self-Disclosure,” Journal of Personality and Social Psychology, 44, 1234-44.

Nunnally, Jum C. (1978), Psychometric Theory, 2nd ed. New York: McGraw-Hill Book Company.

Paulhas, Delroy (1983), "Sphere-Specific Measures of Perceived Control," Journal of Personality and Social Psychology, 44, 1253-65.

- and Carol L. Martin (1988), "Functional Flexibility: A New Conception of Interpersonal Flexibility," Journal of Personality and Social Psychology, 55, 1, 88-101.

Rotter, J. B. (1966), "Generalized Expectancies for Internal Versus External Control of Reinformation," Psychological Monographs, 80 (1, whole \#609).

Snyder, Mark (1979), "Self-Monitoring Processes," in Advances in Experimental Social Psychology, Vol. 12, L. Berkowitz, ed. New York: Academic Press, Inc., 86-128.

Spiro, Rosann L. and William D. Perreault (1979), "Influence Used by Industrial Salespeople: Influence Strategy Mixes and Situational Determinants," Journal of Business, 59 (July), 435-55.

- $\longrightarrow$, and Fred D. Reynolds (1976), "The Personal Selling Process: A Critical Review and Model," Industrial Marketing Management, 5 (Spring), 351-4.

Stanton, William J. (1984), Fundamentals of Marketing, 7th ed. New York: McGraw-Hill Book Company, 469.

Stogdill, Ralph M. (1959), Individual Behavior and Group Achievement. New York: Oxford University Press.

(1963), Manual for the Leader Behavior Description Questionnaire-Form XII. Columbus, $\mathrm{OH}$ : Bureau of Business Research, Ohio State University.

Sujan, Harish and Barton Weitz (1986), "The Effects of Level and Type of Effort on Salesperson Performance," working paper, Pennsylvania State University.

Weitz, Barton A. (1978), "The Relationship Between Salesperson Performance and Understanding of Customer Decision Making," Journal of Marketing Research, 15 (November), 501-16.

(1979), "A Critical Review of Personal Selling Research: The Need for a Contingency Approach," in Critical Issues in Sales Management: State-of-the-Art and Future Research Needs, G. Albaum and G. Churchill, eds. Eugene, OR: College of Business Administration, University of Oregon.

(1981), "Effectiveness in Sales Interactions: A Contingency Framework,” Journal of Marketing, 45 (Winter), 85-103.

- Harish Sujan, and Mita Sujan (1986), “Knowledge, Motivation, and Adaptive Behavior: A Framework for Improving Selling Effectiveness," Journal of Marketing, 50 (October), 174-91.

Wiggins, Jerry S. and Ana Holzmuller (1981), "Further Evidence on Androgyny and Interpersonal Flexibility," Journal of Research in Personality, 15, 67-80. 